\title{
Effect of Cerebellin on the Pituitary-Adrenocortical Function in Adult Rats and the Proliferative Activity of Immature and Regenerating Rat Adrenal Cortex
}

\author{
Ludwik K. Malendowicz', Anna Hochol ${ }^{1}$, Raffaele De Caro², Marcin Trejter ${ }^{1}$, \\ Anna Markowska ${ }^{1}$, Gastone G. Nussdorfer ${ }^{2}$ and Magdalena NowaK ${ }^{1}$ \\ ${ }^{1}$ Department of Histology and Embryology, School of Medicine, Poznan, Poland, and 'Department of Human Anatomy and \\ Physiology, Section of Anatomy, University of Padua, Padua, Italy \\ (Received 1 May 2000; and accepted 11 May 2000)
}

\begin{abstract}
We have investigated the effects of cerebellin on the pituitary adrenal axis and the proliferative activity of immature and regenerating adrenal cortex in the rat. The acute bolus administration of cerebellin did not alter ACTH plasma concentration, but at its higher dose $(15 \mathrm{nmol} / \mathrm{kg})$ the peptide enhanced the blood levels of both aldosterone and corticosterone. Three injections of cerebellin $(10 \mathrm{nmol} / \mathrm{kg})$ markedly increased the mitotic index $(\%$ of metaphase-arrested cells) in the zona glomerulosa of immature rat adrenals. This treatment did not alter either aldosterone or corticosterone plasma concentrations in rats bearing regenerating adrenals, but did it decrease the proliferative activity at day 8 of adrenal regeneration. We conclude that cerebellin exerts its adrenocortical secretagogue and proliferogenic actions acting directly on the adrenal gland of adult and immature rats, independently of any effect on the pituitary ACTH release. The lack of secretagogue effects and the clearcut antiproliferogenic action observed in rats with regenerating adrenals may be ascribed to the effects of cerebellin on the various mechanism involved in this process.
\end{abstract}

Cerebellin, a 16-amino acid peptide originally isolated from rat cerebellum (14), has been subsequently found to be widely distributed in the central nervous system, where it seems to exert neuromodulatory functions $(3,9)$.

The presence of cerebellin in the peripheral tissues is controversial (15). However, cerebellin protein and mRNA has been detected in human adrenal medulla (13). Accordingly, it has been demonstrated that cerebellin enhances catecholamine release by human and rat adrenomedullary fragments $(1,8)$. These investi-

Correspondence to: Prof. G. G. Nussdorfer at the above address.

Tel: $(+39)$ 049-827-2317

Fax:(+39) 049-827-2319

E-mail: ggnanat@ipdunidx.unipd.it gators also provided evidence that cerebellin stimulates steroid hormone secretion by adrenal slices, but not by dispersed adrenocortical cells.

All the above summarized studies were carried out in vitro. Hence, it seemed worth while to investigate the possible effects cerebellin in vivo on the pituitary-adrenocortical axis (PAA) of adult rats and the proliferative activity of immature and regenerating rat adrenals.

\section{MATERIALS AND METHODS}

Adult female Wistar rats (2-month-old, bred in our laboratory) and their offpring (20-day-old) were kept under $12: 12$ h light-dark cycle (illumination onset at $8: 00$ a.m.) at $23^{\circ} \mathrm{C}$, and maintained on a standard diet (Rat-Mouse Chow, Zoofarm, Padua, Italy) and tap water ad libitum. 
The protocol of the experiment was approved by the local Ethical Committee for Animal Studies.

Adult rats were given subcutaneous (s.c.) injections of $0.2 \mathrm{~mL}$ isotonic saline for two weeks in order to dampen the response of their PAA to the handling stress. At day 15, they were divided in three groups, two of which were given a s.c. injection of $0.2 \mathrm{~mL}$ isotonic saline, the vehicle where 5 or $15 \mathrm{mmol} / \mathrm{kg}$ cerebellin (Bachem AG, Bubendorf, Switzerland) were dissolved. Control groups received a s.c. injection of the saline vehicle. All the injections were made at 9:00 a. $\mathrm{m}$., and rats were decapitated 60 or 120 min after the injection (8 rats for each time point).

Under ether anaesthesia, the left adrenal gland was enucleated in a number of rats, and the control ateral gland removed. Operated rats were given $0.9 \% \mathrm{NaCl}$ to drink, and were killed 5 or 8 days after surgery. Groups of immature and operated rats $(\mathrm{n}=8)$ were given three s.c. injections $(28,16$ and $4 \mathrm{~h}$ before the sacrifice) of 0.2 $\mathrm{mL}$ isotonic saline were $10 \mathrm{nmol} / \mathrm{kg}$ cerebellin were dissolved. Control groups received s.c. injections of the saline vehicle. Animals were given an intraperitoneal injection of $0.1 \mathrm{mg} / 100 \mathrm{~g}$ vincristin (Gedeon-Richter, Budapest, Hungary) 180 min before the autopsy.

Rats were decapitated at 11:00 a.m., and the trunk blood was collected in the presence of EDTA $(1 \mathrm{mg} / \mathrm{mL})$. Plasma was separated and stored at $-30^{\circ} \mathrm{C}$ until radioimmune assay (RIA). Adrenal glands were promptly removed and freed of pericapsular fat.

ACTH was extracted from plasma (2), and its concentration measured by RIA: ACTH Double Antibody kit (Diagnostic Products Company, Los Angeles, CA, U. S. A.). Sensitivity: $8 \mathrm{pg} / \mathrm{mL}$. Cross-reactivity: ACTH $(1-24), 100 \% ;(\alpha-\mathrm{MSH}$, $0.3 \%$; other hormones, less than $0.001 \%$. Intra- and interassay variations: $6.2 \%$ and $9.1 \%$, respectively. Aldosterone and corticosterone were extracted from plasma (10), and their concentrations measured by RIA, as described previously (7). Intraand interassay variations were: aldosterone, $5.2 \%$ and $7.5 \%$; corticosterone, $7.3 \%$ and $8.9 \%$, respectively.

Immature adrenals and regenerating glands were fixed in Bouin's solution for $24 \mathrm{~h}$, embedded in paraffin and sectioned at $5-6 \mu \mathrm{m}$. Sections weere stained with hematoxylin and eosin. The mitotic index ( $\%$ of metaphase-arrested cells) was calculated at $400 \times$, by counting 5,000 cells in the zona glomerulosa of each immature gland and in the regenerating adrenal parenchyma.

Data are expressed as means \pm SEM $(n=8)$, and their statistical comparison was done by ANOVA, followed by the Multiple Range Test of Duncan. $P$ values $<0.05$ were considered significant.

\section{RESULTS}

The acute administration of cerebellin did not significantly affect the plasma concentration of ACTH (Fig. 1, upper panel). In contrast, the higher dose of cerebellin induced an about 2.5 -fold increase in aldosterone blood level at both 60 and $120 \mathrm{~min}$ (Fig. 1, middle panel), and a 4.0 -fold rise in corticosterone plasma concentration at 60 min (Fig. 1, lower panel). Cerebellin did not significantly alter either aldosterone or corticosterone plasma concentration in rats bearing regenerating adrenals (Fig. 2).

Cerebellin markedly raised (70\%) mitotic index in the zona glomerulosa of immature rat adrenals (Fig. 3). As expected proliferative activity was higher at day 5 than at day 8 of adrenal regeneration. Cerebellin did not alter mitotic index at day 5 , but reduced it by about $50 \%$ at day 8 of regeneration (Fig. 4).

\section{DISCUSSION}

It has been previously found that cerebellin stimulates steroid secretion by human and rat adrenal quarters, and our present results confirm in vivo these findings. They also show that this peptide markedly enhances the proliferative activity of the zona glomerulosa, the "cambium layer" involved in the maintenance of adrenal growth (11). Cerebellin does not affect plasma ACTH concentration, which makes unlikely the possibility that its stimulating effect on adrenals may be dependent on any action on the pituitary ACTH release.

Adrenal regeneration after enucleation is an experimental model where remnant subcapsular zona glomerulosa cells rapidly dedifferentiate and start to proliferate restoring a normal adrenocortical morphology in about 30-60 days. Adrenocortical cell dedifferentiation is coupled with their impaired ability to secrete aldosterone and corticosterone (for review, see 11), which explains the rather low plasma concentrations of these two hormones in operated rats as compared to adult intact animals (Figs. 1 and 2).

We have previously demonstrated that cerebel- 

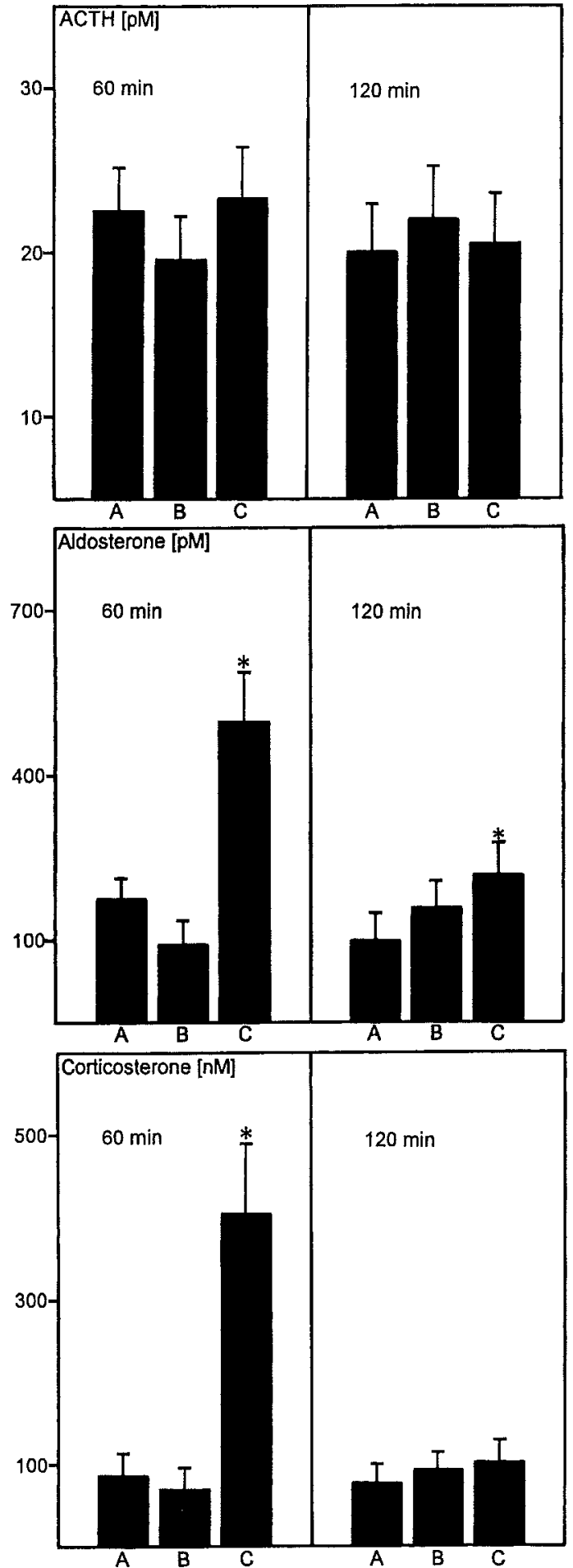

Fig. 1 Acute effect of cerebellin on ACTH (upper panel), aldosterone (middle panel) and corticosterone (lower panel) plasma concentrations in the rat. A, control; B, cerebellin $5 \mathrm{nmol} / \mathrm{kg}$; $\mathrm{C}$, cerebellin 15 $\mathrm{nmol} / \mathrm{kg}$. Bars are means \pm SEM $(\mathrm{n}=8) .{ }^{*} P<0.01$ from the respective control value.

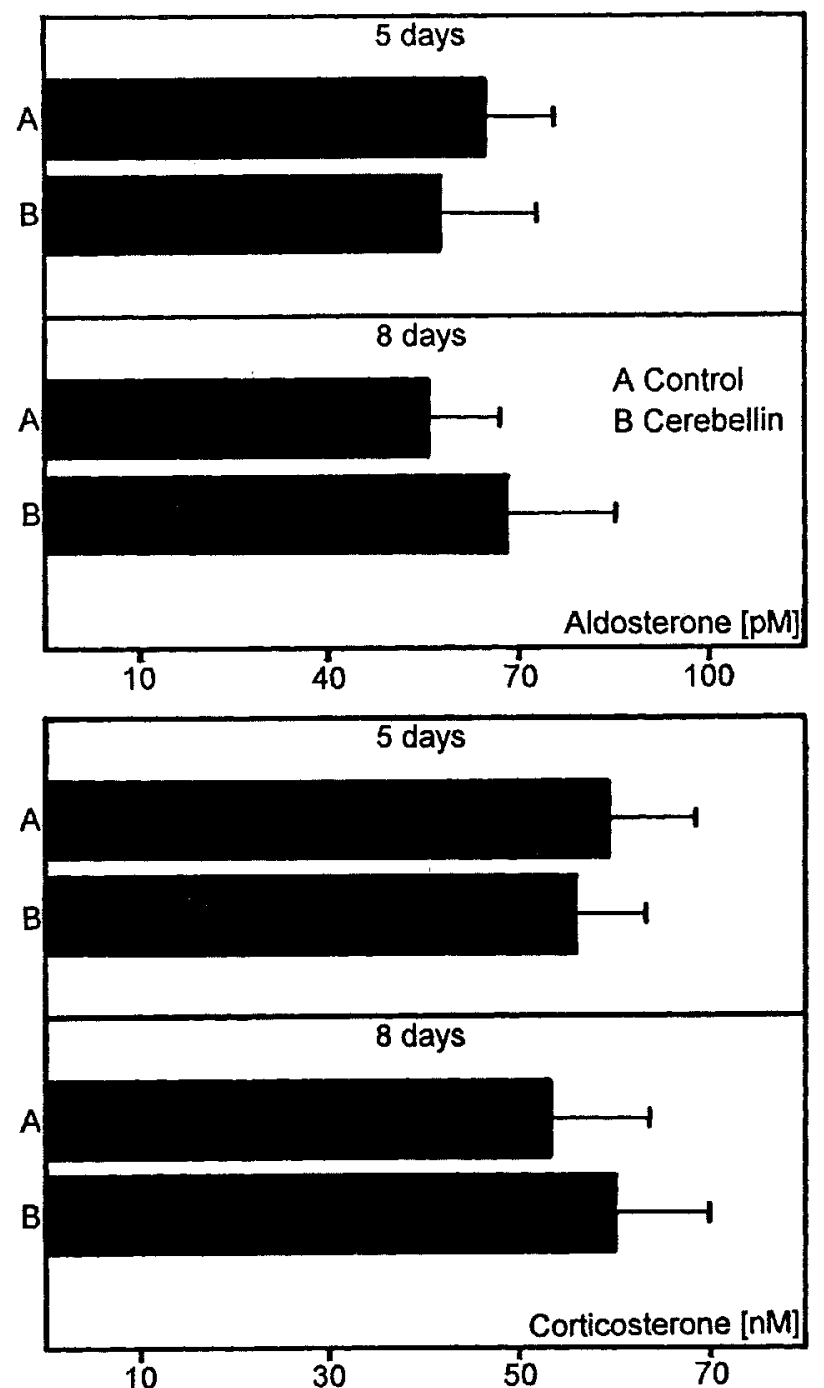

Fig. 2 Lack of effect of cerebellin on aldosterone (upper panels) and corticosterone plasma concentrations (lower panels) in rats bearing regenerating adrenals. Bars are means \pm SEM $(n=8)$.

lin stimulates steroid secretion indirectly, by eliciting catecholamine release that in turn activate adrenocortical cells. In fact, the in vitro adrenocortical secretagogue action of cerebellin is blocked by the antagonists of $\beta$-adrenoceptors ( 1 , 8 ). Enucleation eliminates medullary tissue, and consequently in regenerating adrenals chromaffin cells are lacking (11). This consideration may easily explain why cerebellin does not affect aldosterone and corticosterone secretion from regenerating rat adrenals.

Although cerebellin enhances proliferative activity of zona glomerulosa of immature rat 


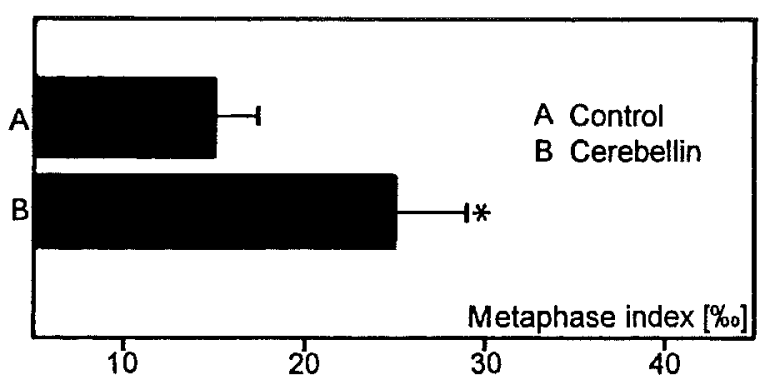

Fig. 3 Effect of cerebellin on the proliferative activity of the zona glomerulosa of immature rat adrenal cortex. Bars are means \pm SEM $(n=8) .{ }^{*} P<0.01$ from the respective control value.

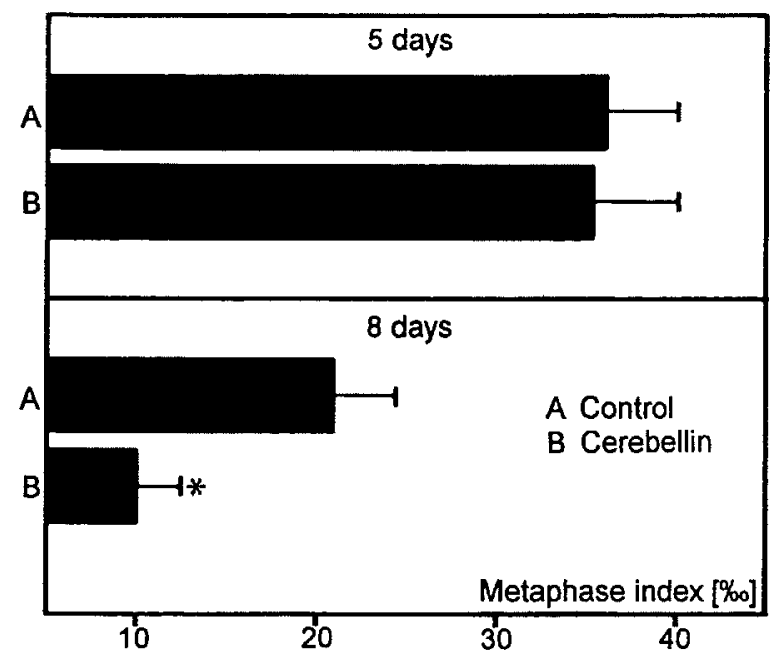

Fig. 4 Effect of cerebellin on the proliferative activity of regenerating rat adrenal glands. Bars are means $\pm \operatorname{SEM}(\mathrm{n}=8)$. ${ }^{*} P<0.01$ from the respective control value.

adrenals, our findings indicate that the peptide decreases mitotic index at day 8 of regeneration. At present, we are not able to provide a possible explanation of these conflicting results. However, we want to stress that they are in keeping with the contention that different mechanisms are involved in the normal growth and regeneration of adrenal glands. In contrast with normal adrenal growth, adrenal regeneration involves complex neural mechanism (4-6), which could be negatively modulated by cerebellin.

In conclusion, our study provides the first in vivo evidence that cerebellin, acting directly on rat adrenal gland, exerts various secretory and growth effects, which depend on the experimental model employed. Hence our findings allow us to include cerebellin in that group of peptides which modulate adrenal secretion and growth acting in a paracrine manner (12).

\section{REFERENCES}

1. Albertin G., Malendowicz L. K., Macchi C., Markowska A. and Nussdorfer G. G. (2000) Cerebellin stimulates the secretory activity of the rat adrenal gland: $I n$ vitro and in vivo studies. Neuropeptides 34, 1-5.

2. Andreis P. G., Neri G., Mazzocchi G., Musajo F. G. and Nussdorfer G. G. (1992) Direct secretagogue effect of corticotropin-releasing factor on the rat adrenal cortex: The involvement of the zona medullaris. Endocrinology 131, 69-72.

3. Burner P. W. J., Bretherton-Watt D., Ghatei M. A. and Bloom S. R. (1988) Cerebellin-like peptide: tissue distribution in rat and guinea-pig and its release from rat cerebellum, hypothalamus and cerebellar synaptosomes in vitro. Neuroscience 25, 605-612.

4. Engeland W. C. and Levay-Young B. K. (1999) Changes in the glomerulosa cell phenotype during adrenal regeneration in rats. Am. J. Physiol. 276, R1374-R1382.

5. Gragg R. D. and Soliman K. F. A. (1993) Biochemical evidence for peripheral neural regulation of adrenocortical regeneration in response to bilateral adrenal enucleation. Life Sci. 53, 275-282.

6. Holzwarth M. A., Shinsako J. and Dallman M. F. (1980) Adrenal regeneration. Time course, effect of hypothalamic hemi-islands and response to unilateral adrenalectomy. Neuroendocrinology 31, 168-176.

7. Malendowicz L. K., Nussdorfer G. G., Nowak K. W. and Mazzocchi G. (1994) The possible involvement of galanin in the modulation of the function of rat pituitaryadrenocortical axis under basal and stressful conditions. Endocrine Res. 20: 307-317.

8. Mazzocchi G., Andreis P. G., De Caro R., Aragona F., Gottardo L. and Nussdorfer G. G. (1999) Cerebellin enhances in vitro secretory activity of human adrenal gland. J. Clin. Endocrinol. Metab. 84, 632-635.

9. Mugnaini E., Dahl A. L. and Morgan J. I. (1988) Cerebellin is a postsynaptic neuropeptide. Synapse 2, 125138.

10. Neri G., Malendowicz L. K., Andreis P. G. and Nussdorfer G. G. (1993) Tyrotropin-releasing hormone inhibits glucocorticoid secretion of rat adrenal cortex: in vivo and in vitro studies. Endocrinology 133, 511-514.

11. Nussdorfer G. G. (1986) Cytophysiology of the adrenal cortex. Int. Rev. Cytol. 98, 1-405.

12. Nussdorfer G. G. (1996) Paracrine control of adrenal cortical function by medullary chromaffin cells. Pharmacol. Rev. 48, 495-530.

13. Satoh F., Takahashi K., Murakami O., Totsune K., Ohneda M., Mizuno Y., Sone M., Miura Y., Takase S., Hayashi Y., Sasano H. and Mouri T. (1997) Cerebellin and cerebellin mRNA in the human brain, adrenal glands and the tumour tissues of adrenal tumour, ganglioneuroblastoma and neuroblastoma. J. Endocrinol. 154, 27-34.

14. Slemmon G. R., Blacher R., Danho W., Hempstead J. L. and Morgan J. I. (1984) Isolation and sequencing of two cerebellum-specific peptides.' Proc. Natl. Acad. Sci. USA 81, 6866-6870.

15. Urade Y., Oberdick J., Molinar-Rode R. and Morgan J. I. (1991) Precerebellin is a cerebellum-specific protein with similarity to the globular domain of complements Clq B chain. Proc. Natl. Acad. Sci. USA 88, 1069-1073. 